\title{
Impact of Mild Hypothermia on Final Outcome of Patients with Acute Stroke: A Randomized Clinical Trial
}

\author{
Abbas Rouzbahani ${ }^{1}$ Esmail Khodadadi ${ }^{2}$ Marjaneh Fooladi ${ }^{3}$ \\ ${ }^{1}$ Nursing and Midwifery School, Islamic Azad University, Urmia, Iran \\ 2Iranian Social Security Organization, Urmia, Iran \\ ${ }^{3}$ World Wide Nursing Service Network, PLLC, El Paso, Texas, \\ United States \\ Address for correspondence Esmail Khodadadi, PhD, Iranian Social \\ Security Organization, Urmia, Iran \\ (e-mail: esmailkhodadadi11@gmail.com).
}

Indian J Neurotrauma:2020;17:17-23

\begin{abstract}
Keywords

- hypothermia

- stroke

- randomized clinical trial

- disease outcome

Background and Aim Stroke is a sudden neurological disorder caused by disturbances in the brain blood flow and loss of normal brain function. Stroke is also the second leading cause of death worldwide. In the last two decades, among the various treatment options for stroke, hypothermia has shown the promise of improving the final outcome. This study aimed to investigate the effect of noninvasive hypothermia on the final outcome of patients with an acute stroke in Iran.

Methods In a randomized clinical trial, 60 Iranian patients diagnosed with acute stroke were enrolled in 2018. Patients were selected by convenience sampling method and then randomized in two groups as experimental $(n=30)$ and control $(n=30)$. Mild hypothermia was applied using a cooling device for 72 hours on the patients' heads and intervention results were compared with the control group. Data were collected by using Acute Physiology and Chronic Health Evaluation III (APACHE III), Full Outline of Un-Responsiveness (FOUR), and National Institutes of Health Stroke Scale (NIHSS), and later analyzed by Statistical Package for the Social Sciences (SPSS) software version 22. Results No significant difference was found in the mean scores of all three scales before and after the intervention in control group $(p>0.05)$ but statistically significant difference was found in the mean scores of all three scales for the intervention group $(p<0.05)$. The intervention group had an increased mean score in FOUR, while APACHE and NIHSS values dropped. Researchers found statistically significant difference between the mean scores after the intervention in the experimental group compared with the control group in all three scales $(p<0.05)$.

Conclusion The findings of this study indicate that hypothermia has a significant statistical and clinical effect on the acute stroke outcome and it can be argued that hypothermia therapy can increase the level of consciousness and reduce the risk of death in stroke patients.
\end{abstract}

\section{Introduction}

Stroke is a sudden neurological disorder triggered by abnormalities in the cerebral blood vessels, leading to perfusion disorder in the affected areas of stroke. In other words, stroke means an impaired or blocked perfusion in one or more parts of the brain leading to disruption of its normal functions. ${ }^{1}$ Stroke patients are immediately hospitalized to prevent permanent brain damage. ${ }^{2}$ In severe cases of stroke, major organs are damaged leading to paralysis, coma, numbness, sensory disturbances, confusion, mental disorders, and speech impediment. Some of the preventable risk

(C)2020 Neurotrauma Society of India

License terms

()(1) $\Theta \circledast$ 
factors for stroke are hypertension, hypercholesterolemia, smoking, and alcohol consumption. ${ }^{3}$

The review of literature shows that stroke is the second most common cause of death worldwide and the third leading cause of death in the western industrialized countries. Nearly $10 \%$ of all deaths in the world are caused by stroke. In the United States alone, 780,000 cases of strokes are reported every year. ${ }^{4}$ Two-thirds of all strokes in the world happen in developing countries. It has been estimated that the number of deaths from stroke in the Middle East and North Africa will double by $2030 .{ }^{5}$ The study results show that mortality rates due to stroke are higher in Asia than in the Americas and Europe. ${ }^{6}$ Asia has almost two-thirds of the world population, and in 2002, approximately $60 \%$ of the world's deaths from stroke occurred in East Asia. ${ }^{7}$ Similarly, the incidence of acute ischemic stroke in Iran has reached 139 per 100,000 in lower age groups compared with the global average age and a higher mortality rate compared with the developed countries. ${ }^{8}$

More than 80 to $85 \%$ of strokes are ischemic type, caused by cerebrovascular occlusive disease followed by thrombosis or embolism. Less than 10 to $15 \%$ of the stroke cases are from cerebral hemorrhage. ${ }^{9}$ The etiology of stroke determines treatment approach. For ischemic stroke, treatment is focused on: reducing or limiting the damage to the infarcted area with thrombolytic drugs and medical support; preserving blood flow through invasive endovascular methods and anticoagulant therapy; and an immediate effort to maintain the integrity of nerves in the brain. In hemorrhagic stroke, prognosis is mainly determined by the volume of blood loss and location of hemorrhage in the brain. Controlling brain edema and lowering intracranial pressure (ICP) via osmotic drugs and sometimes corticosteroids are critical steps. ${ }^{3}$

Recently, among different modes of intervention, hypothermia has been recognized for improving the final outcome of the diseases. ${ }^{10}$ Hypothermia was first introduced in cardiac patients after cardiopulmonary resuscitation (CPR) studies showed that hypothermia was very effective. ${ }^{11,12}$ Researchers hypothesized that mild hypothermia after stroke could reduce the neurological damage and delay brain death. ${ }^{13}$ Therefore, hypothermia was accepted as an effective intervention for reducing ICP in patients with traumatic brain injury. ${ }^{14,15}$

Other empirical studies supported the neurological effects of hypothermia. ${ }^{16,17}$ Neuroprotective mechanism of hypothermia stabilizes blood-brain barrier, lowers brain metabolism, reduces the release of neurotransmitters, and delays production of free radicals. ${ }^{18}$ Some studies have examined the protective effects of hypothermia by focusing on the hypothermic starting time, duration, and depth, as well as the outcome. ${ }^{19,20}$ Long-term hypothermia has shown some adverse effects, such as cardiac dysrhythmia and increased blood coagulation. ${ }^{19}$ Moreover, in recent studies, hypothermic therapies combined with other strategies such as drugs are being examined. ${ }^{21}$

No study in Iran has explored the effects of hypothermia after an acute stroke. However, some Iranian studies have shown the effectiveness of hypothermia in other medical conditions. For instance, Basiri et al reported that topical hypothermia significantly lowered the seizure rates in infants with ischemic encephalopathy compared with infants receiving a conventional treatment. ${ }^{22}$ Ehsani et al found that application of general hypothermia in rats significantly reduced the rate of myocardial infarction and neurological disorders by having neuroprotective effects. ${ }^{23}$

Among the treatment options for stroke patients, hypothermia has shown improvement in the final outcome of the disease and has provided evidence in efficacy and efficiency as a noninvasive approach after CPR, especially for patients with traumatic brain injury. The noninvasive mode of hypothermia in acute stroke is a logical approach and not fully investigated. Given the high rate of stroke and mortality among the young Iranians, and the noninvasive efficacy of hypothermia for treating acute stroke, it appeared prudent to design an investigative study to examine the effect of hypothermia on the final outcome of admitted patients with acute stroke in the city of Hamadan in Iran.

\section{Materials and Methods}

\section{Design}

In a single-blind randomized clinical trial, 60 Iranian stroke patients admitted to the intensive care units (ICUs) of several teaching hospitals affiliated with the Hamadan University of Medical Sciences were selected for this study using convenience sampling. In addition, patients with acute stroke admitted to the ICUs at government hospitals were also included in the study sample. The required sample size was determined by considering $95 \%$ confidence level and $(\alpha=0.05)$ using the formula $n=\left(z_{1-\alpha / 2}+z_{1-\beta}\right)^{2}\left(\sigma^{2}{ }_{1}+\sigma_{2}^{2}\right)^{2} / d^{2}$ based on similar studies. ${ }^{24,25}$

Initially our sample was set for 70 patients, but, through exclusion criteria, only 60 patients qualified for participation. Therefore, 60 Iranian patients were equally and randomly assigned into experimental and control groups (-Fig. 1). Participants were coded and equally assigned to two groups $(n=30)$ using random numbers generator by software. Both groups were homogeneous in terms of their demographic characteristics. After the sample selection and coordination with the physicians, informed consents were obtained to collect data using survey questionnaires. Both data collection and data analysis were completed by a researcher who was blinded to group allocations.

\section{Inclusion and Exclusion Criteria}

Inclusion criteria were: having had a hemorrhagic or ischemic stroke, age over 18 , no severe heart failure, no pulmonary embolism or acute myocardial infarction, no acute or chronic sinusitis or current fracture of the skull bone, no septicemia or bacteremia or severe sepsis on admission, and no fever above $38.5^{\circ} \mathrm{C}$ during hospitalization period. The exclusion criteria were: death in less than 24 hours upon admission, unexpected complications such as intolerance, seizure, shivering, and so on, cardiac dysrhythmia, and the request by the patient or legal guardian to exit the study. 


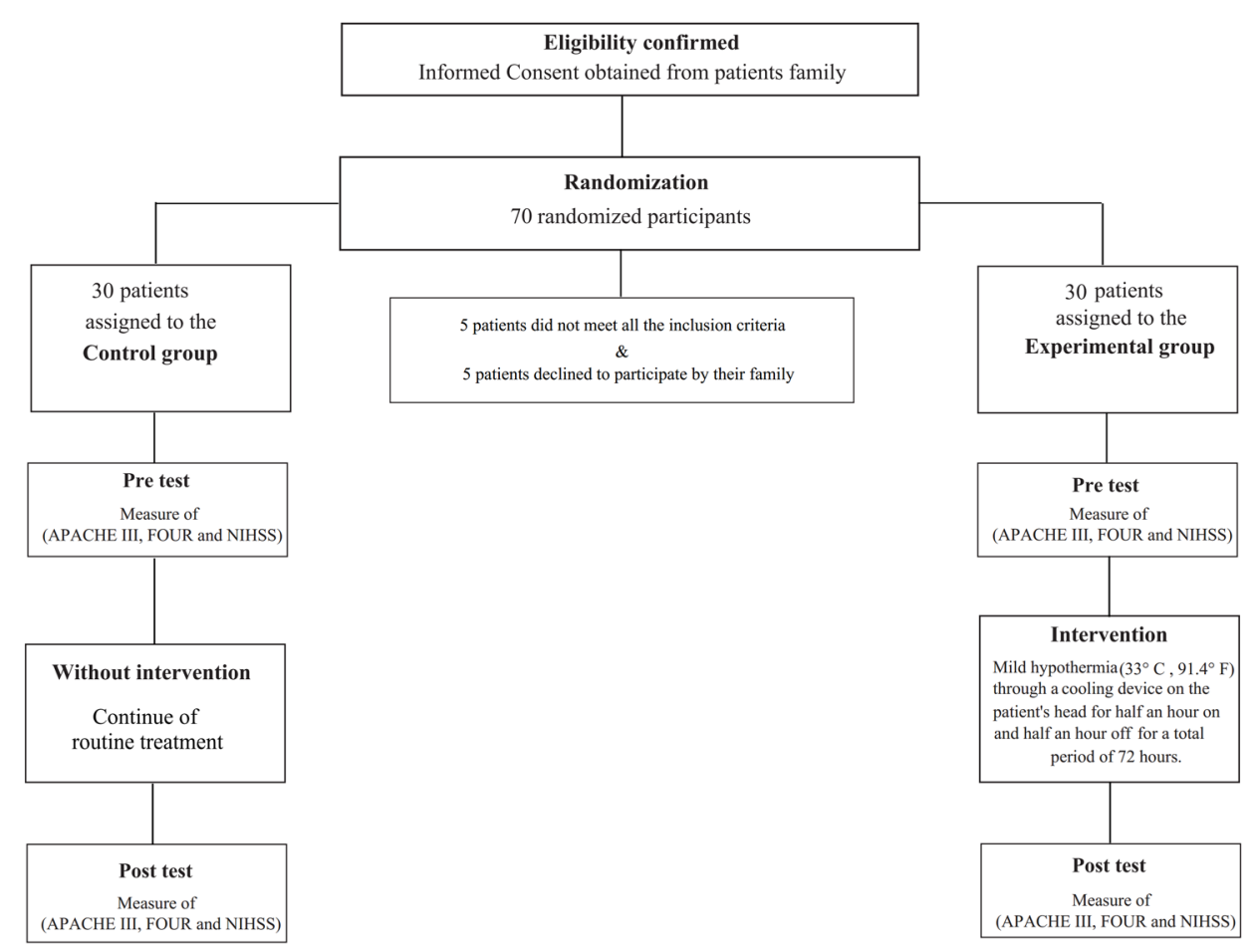

Fig. 1 Flow chart of the study. APACHE, Acute Physiology and Chronic Health Evaluation; FOUR, Full Outline of Un-Responsiveness; NIHSS, National Institutes of Health Stroke Scale.

\section{Intervention}

The experimental group received mild hypothermia and control group received the routine hospital treatment as per the protocol. The intervention consisted of applying mild hypothermia $\left(33^{\circ} \mathrm{C}\right.$, equal to $\left.91.4^{\circ} \mathrm{F}\right)$ through a cooling device (helmet) on the patients' heads for half an hour on and half an hour off for a period of 72 hours in total. See - Appendix (online-only) for the map of cooling device and brain computed tomography scan images.

\section{Instruments}

Data collection process employed demographic questionnaire, Acute Physiology and Chronic Health Evaluation III (APACHE III), Full Outline of Un-Responsiveness (FOUR) Score, and National Institutes of Health Stroke Scale (NIHSS) tools. The demographic questionnaire obtained information about age, gender, social status, occupation, education, underlying illness, and the type of stroke. APACHE III Questionnaire is a scoring scale for ICU patients, where the physicians estimate the prognosis and the rate of improvement in stroke patients. This tool has three parts; the first part has 11 items for measuring physiological variables and 1 item for the Glasgow coma scale (GCS). The minimum score of each question in the physiological dimension is 0 and maximum is 4 . The 11 items used to evaluate physiological aspects are temperature: mean arterial blood pressure, heart rate, respiratory rate, $\mathrm{pH}$, arterial blood $\mathrm{PaO}_{2}$, sodium and potassium, serum creatinine, hematocrit, and white blood cell counts. The minimum score in the physiologic aspect is 0 and maximum is 59. The GCS score starts from 0 (the highest level of consciousness) to 12 (the lowest level of consciousness).
The second part of the instrument scores the patient based on age group, where 0 point is given to patients less than or equal to 44 years of age, 2 points for 45 to 54 years old, 3 points for 55 to 64 years old, 5 points for 65 to 74 years of age, and 6 points for older than 75 years. The third section evaluates the condition of a person's chronic illness with a scoring range of 0 to 71 points. The higher score means a greater deterioration of the patient's health condition. The validity and reliability of this tool have been confirmed by Knaus et al abroad and Soleimani et al and Motamed Al-Shariati et al in Iran. ${ }^{26-28}$

FOUR Score tool is a relatively new scale introduced as a good successor to GCS. Unlike GCS, FOUR score does not examine verbal function, but it can more accurately examine and scale an intubated coma patient with tracheotomy. This scale has four parts: visual response, motor response, brain stem response, and respiration pattern, with a maximum score of 4 and a minimum score of 0 . The overall score would be from 0 to 16 and a higher score means better consciousness level. The validity and reliability of this tool have been approved in other studies by Wijdicks et al, Wolf et al, Iyer et al, Cohen, and by Tadrisi et al in Iran. ${ }^{29-33}$

The stroke scale or NIHSS is a tool used to evaluate the degree of disturbance to brain function caused by stroke. The tool has 11 items and 7 subscales. Item 1 has 3 subscales and items 5 and 6 each have 2 subscales. Points in some items are from 0 to 2 and in some from 0 to 4 . The scores for each item are collected to calculate the total score of the patient's NIHSS scale. Maximum score is 42 and minimum is 0 , with the higher score showing more brain damage. The validity and reliability of NIHSS scoring system were confirmed by Kasner et al as well as Hinkle abroad and by Kazemnejad et al in Iran. ${ }^{34-36}$ 


\section{Statistical Analysis}

In this study, the final analyses were generated by statistical software Statistical Package for the Social Sciences (SPSS; version 22) to reach descriptive and inferential results. Charts, frequency tables, percentages, mean scores, and standard deviations were used at the descriptive level. Kolmogorov-Smirnov $t$-test, and paired $t$-test were used in inferential statistics. The significance level of $\alpha$ was set at less than 0.05 with a confidence level of $95 \%$.

\section{Ethical Considerations}

Researchers obtained internal review board approval from the Ethics Committee of Islamic Azad University in Urmia. Informed consent for participation in the study was obtained from all the patients or their legal guardians and coding was used for privacy and confidentiality of data.

\section{Results}

The mean age of participants was $58.18 \pm 11.28$, with an equal number of men and women. They were mostly married, indicated low literacy level, smoked, and had moderate economic status as seen in - Table 1. Additionally, the study results showed a normal data distribution suitable for using $t$-test and paired $t$-test to compare scores in the groups. The results of the Kolmogorov-Smirnov test showed the normality of data in both groups. The paired $t$-test results showed no significant differences in any of the three scales between the mean scores before and after the intervention in control group $(p>0.05)$. Independent $t$-test results also indicated no significant difference in any of the three scales between the mean scores before intervention in the experimental group compared with the control group ( $p>0.05 ;-$ Fig. 2, -Table 2).

The results of independent $t$-test showed a significant difference in all three scales between the mean scores after the intervention in experimental group compared with the control group $(p<0.05)$. Furthermore, the results of paired $t$-test showed a significant difference between the mean scores before and after intervention in the experimental group $(p<0.05)$, and the mean scores of FOUR scale increased after intervention compared with before in the experimental group by a reduction in APACHE and NIHSS scales. As presented in - Table 3, the study results show that hypothermic intervention in acute stroke has a statistically significant effect on the final recovery outcome ( - Fig. $3,-$ Table 3 ).

\section{Discussion}

We found a significant difference between the mean scores after the intervention in the experimental group compared with the control group in all three scales. Also, we found a significant difference between the mean scores before and after the intervention in the experimental group in all three scales. Hence, hypothermia has a statistically significant effect on the improvement of the patient's status and outcome after an acute stroke. Consistent with our results other studies show the positive effects of hypothermia in various fields, 18,37-39 and hence it has been considered as one of the significant treatments for stroke patients in the last two decades. ${ }^{18,20,40}$

Several studies have shown the neuroprotective effect of hypothermia. ${ }^{19,41-43}$ Schultheiss et al concluded that hypothermia could protect retina ganglion cells against ischemia and increase the ischemic tolerance time for optic cells. ${ }^{41}$ Moreover, research evidences show that hypothermia has a neuroprotective role for patients suffering from subarachnoid hemorrhages, ${ }^{44}$ encephalopathy, ${ }^{10}$ and cerebral edema due to stroke, ${ }^{45}$ which supports this study results.

Andresen et al used endoscopic hypothermia to treat patients with acute brain injuries. The efficacy of hypothermia in brain damage was confirmed when researchers

Table 1 Frequency distribution of study participants

\begin{tabular}{|c|c|c|c|c|c|}
\hline \multicolumn{2}{|c|}{ Variables } & \multirow{2}{*}{$\begin{array}{l}\text { Frequency (\%) } \\
18(30)\end{array}$} & \multicolumn{2}{|c|}{ Variables } & \multirow{2}{*}{$\begin{array}{l}\text { Frequency (\%) } \\
34(56.7)\end{array}$} \\
\hline Gender & Female & & Smoking & Yes & \\
\hline & Male & $42(70)$ & & No & $26(43.3)$ \\
\hline \multirow[t]{2}{*}{ Marital status } & Married & $51(85)$ & \multirow[t]{2}{*}{ Hypertension } & Yes & $44(73.3)$ \\
\hline & Single & $9(15)$ & & No & $16(26.7)$ \\
\hline \multirow[t]{4}{*}{ literacy level } & Uneducated & $14(23.3)$ & \multirow[t]{2}{*}{ Diabetes } & Yes & $23(55)$ \\
\hline & Elementary & $13(21.6)$ & & No & $27(45)$ \\
\hline & Diploma & $10(16.6)$ & \multirow[t]{2}{*}{ Hypercholesterolemia } & Yes & $40(66.7)$ \\
\hline & Bachelor & $13(21.6)$ & & No & $20(33.3)$ \\
\hline \multirow[t]{3}{*}{ Occupation } & Self-employment & $16(26.7)$ & \multirow[t]{2}{*}{ Type of stroke } & Ischemic & $41(68.3)$ \\
\hline & Housekeeper & $23(38.3)$ & & Hemorrhagic & $19(31.7)$ \\
\hline & Employee & $21(35)$ & \multirow[t]{2}{*}{ History of stroke } & Yes & $29(48.3)$ \\
\hline \multirow{3}{*}{$\begin{array}{l}\text { Economic } \\
\text { status }\end{array}$} & Weak & $12(20)$ & & No & $31(51.7)$ \\
\hline & Moderate & $25(41.7)$ & $\mathrm{Age}^{\mathrm{a}}$ & \multicolumn{2}{|c|}{$58.18 \pm 11.2$} \\
\hline & Good & $23(38.3)$ & $\mathrm{BMI}^{\mathrm{a}}$ & \multicolumn{2}{|c|}{$29.54 \pm 5.5$} \\
\hline
\end{tabular}

${ }^{a}$ For these variables, mean (standard deviation) is reported. 


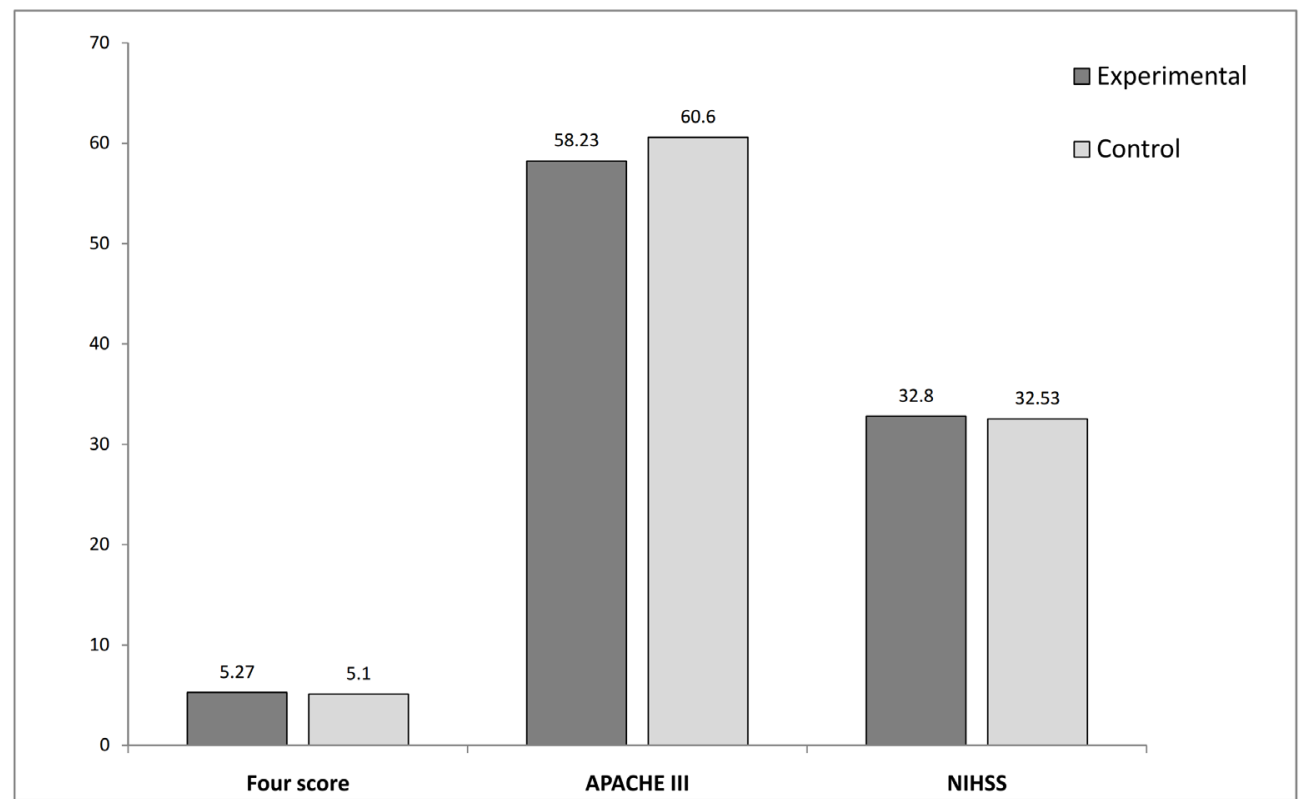

Fig. 2 Comparison of mean scores between experimental and control group before intervention. APACHE, Acute Physiology and Chronic Health Evaluation; FOUR, Full Outline of Un-Responsiveness; NIHSS, National Institutes of Health Stroke Scale.

Table 2 Comparison of mean scores between experimental and control groups

\begin{tabular}{|c|c|c|c|c|c|c|}
\hline \multirow[t]{2}{*}{ Variables } & \multicolumn{2}{|c|}{ Control group } & \multirow[t]{2}{*}{$p$-Value } & \multicolumn{2}{|c|}{ Experimental group } & \multirow[t]{2}{*}{$p$-Value } \\
\hline & $\begin{array}{l}\text { Before } \\
\text { intervention }\end{array}$ & $\begin{array}{l}\text { After } \\
\text { intervention }\end{array}$ & & $\begin{array}{l}\text { Before } \\
\text { intervention }\end{array}$ & $\begin{array}{l}\text { After } \\
\text { intervention }\end{array}$ & \\
\hline APACHE III & $60.60 \pm 4.17$ & $61.00 \pm 4.06$ & $p=0.071$ & $58.23 \pm 5.75$ & $18.37 \pm 9.13$ & $p=0.000^{\mathrm{a}}$ \\
\hline FOUR score & $5.10 \pm 2.18$ & $5.33 \pm 2.13$ & $p=0.090$ & $5.27 \pm 2.10$ & $11.17 \pm 2.58$ & $p=0.000^{\mathrm{a}}$ \\
\hline NIHSS & $32.53 \pm 5.37$ & $32.10 \pm 5.44$ & $p=0.708$ & $32.80 \pm 3.07$ & $17.10 \pm 9.0$ & $p=0.000^{\mathrm{a}}$ \\
\hline
\end{tabular}

Abbreviations: APACHE, Acute Physiology and Chronic Health Evaluation; FOUR, Full Outline of Un-Responsiveness; NIHSS, National Institutes of Health Stroke Scale.

andicates statistical significance $(p<0.05)$.

noted reduced brain tissue metabolism, oxygen demand, less inflammation, prevention of adenosine triphosphate reserves depletion, and the reduction of free radicals. ${ }^{19}$ In another study by Jeong et al, a widespread use of hypothermia in elderly patients diagnosed with malignant brain edema was deemed as safe and practical with positive results. Researchers argued that hypothermia is an effective alternative treatment for reducing cerebral edema pressure among the elderly patients. ${ }^{39}$ Likewise, Bi et al concluded that mild hypothermia helps minimal hematoma discharge by reducing inflammation and damage to the brain cells after stroke, ${ }^{42}$ which is consistent with the results of our study.

However, long-term hypothermia, especially as an invasive procedure, could have adverse effects, ${ }^{46,47}$ as Poli et al showed that nasopharyngeal and infusion-induced hypothermia in stroke patients had severe and unpleasant outcomes. ${ }^{48}$ In their review study, Tahir and Pabaney concluded that although hypothermia has been used to manage stroke in recent years, its effectiveness is still controversial. ${ }^{49}$ Alzaga et al argued that despite high risk and some complications, hypothermia can improve outcomes for patients after stroke, cardiac arrest, brain trauma, asphyxiated infants, and those with elevated ICP. They concluded that hypothermia use and its outcome should be further examined to reduce procedural complications. ${ }^{43}$ Kurisu and Yenari showed that hypothermia has positive and protective effects on important organs and will improve patient outcomes after stroke, but more investigations are needed to reduce adverse effects. ${ }^{18}$

\section{Summary}

Hypothermia has significant statistical and clinical effects on acute stroke. In patients with acute stroke, use of hypothermia therapy increases the level of consciousness and the mean of FOUR score but decreases the mean of APACHE and NIHSS scores.

\section{Conclusions}

Supported by research literature, our results indicate that use of hypothermia can decrease fatality risks after stroke. We found that hypothermia improves the final outcome for stroke patients by enhancing their recovery poststroke. Accordingly, we recommend replication of this study in a larger group to 


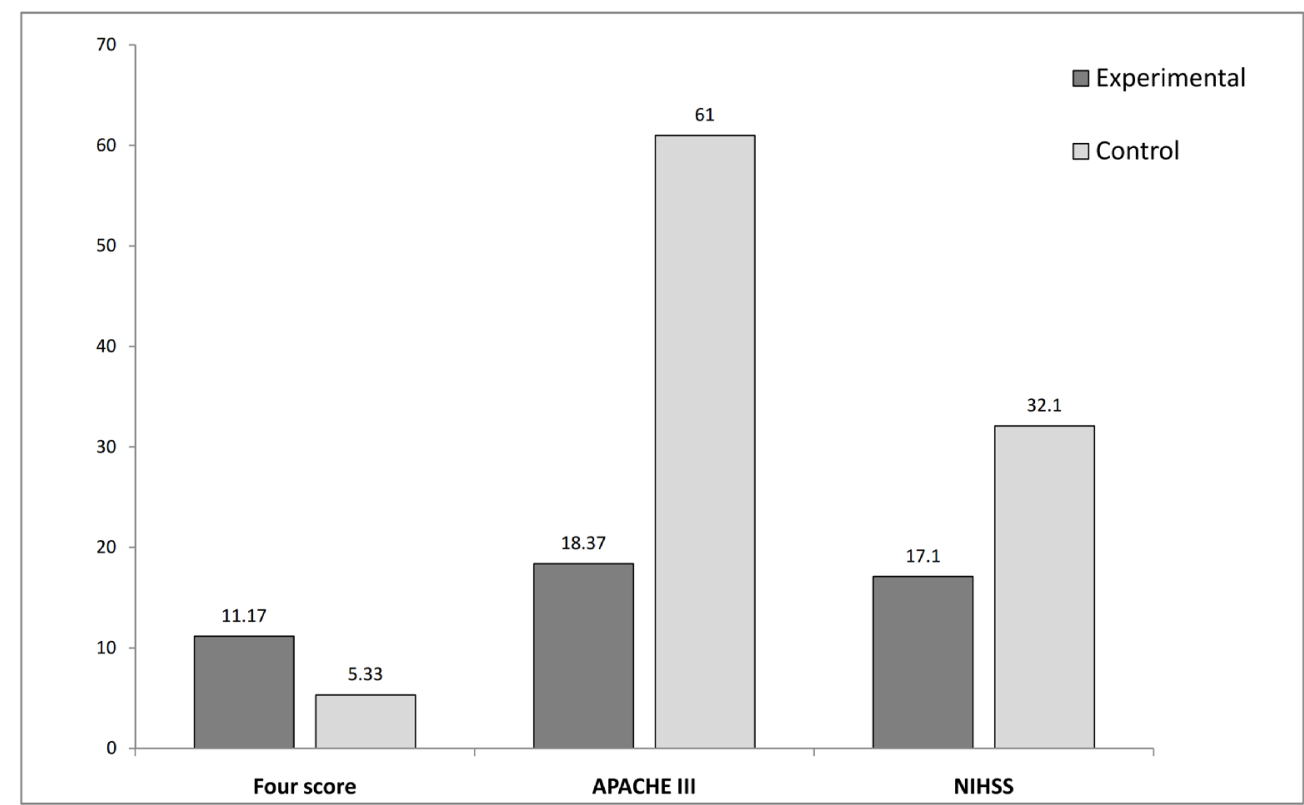

Fig. 3 Comparison of mean scores between experimental and control group after intervention. APACHE, Acute Physiology and Chronic Health Evaluation; FOUR, Full Outline of Un-Responsiveness; NIHSS, National Institutes of Health Stroke Scale.

Table 3 Comparison of mean scores between experimental and control groups

\begin{tabular}{|l|l|l|l|l|l|l|}
\hline & \multicolumn{3}{|c|}{ Before intervention } & \multicolumn{3}{c|}{ After intervention } \\
\cline { 2 - 7 } & APACHE III & FOUR score & NIHSS & APACHE III & FOUR score & NIHSS \\
\hline Control group & $60.60 \pm 4.17$ & $5.10 \pm 2.18$ & $32.53 \pm 5.37$ & $61.00 \pm 4.06$ & $5.33 \pm 2.13$ & $32.10 \pm 5.44$ \\
\hline Experimental group & $58.23 \pm 5.75$ & $5.27 \pm 2.10$ & $32.80 \pm 3.07$ & $18.37 \pm 9.13$ & $11.17 \pm 2.58$ & $17.10 \pm 9.0$ \\
\hline p-Value & $p=0.073$ & $p=0.764$ & $p=0.815$ & $p=0.000^{\mathrm{a}}$ & $p=0.000^{\mathrm{a}}$ & $p=0.000^{\mathrm{a}}$ \\
\hline
\end{tabular}

Abbreviations: APACHE, Acute Physiology and Chronic Health Evaluation; FOUR, Full Outline of Un-Responsiveness; NIHSS, National Institutes of Health Stroke Scale.

andicates statistical significance $(p<0.05)$.

specify the most effective aspects of hypothermia treatment in terms of temperature level and duration period. We suggest that healthcare administrators consider use of hypothermia for stroke and other patients in Iran, especially for burn patients and those with different malignancies.

\section{Conflict of Interest}

The author(s) declared no potential conflict of interest with respect to the research, authorship, and/or publication of this article.

\section{Ethical Approval}

This study was approved by the Ethics Committee of Islamic Azad University, Urmia, and issued a number: IR.IAU.URMIA.REC.1397.12

\section{Sources of Funding}

The study was supported by Islamic Azad University, Urmia.

\section{Acknowledgments}

This study is a part of Master's degree dissertation in nursing. Authors are grateful for support of the administrators at Hamadan University of Medical Science and Nurses. Authors also thank all of the patients and their families for participating in this study.

\section{References}

1 Goetz CG, ed. Textbook of Clinical Neurology. Philadelphia, PA: Elsevier Health Sciences,; 2007

2 Bradley WG, ed. Neurology in Clinical Practice: Principles of Diagnosis and Management. Abingdon: Taylor \& Francis; 2004

3 Malani PN. Harrison's principles of internal medicine. JAMA 2012;308:1813-1814

4 Daneshfard B, Izadi S, Shariat A, Toudaji MA, Beyzavi Z, Niknam L. Epidemiology of stroke in Shiraz, Iran. Iran J Neurol 2015;14(3):158-163

5 Tran J, Mirzaei M, Anderson L, Leeder SR. The epidemiology of stroke in the Middle East and North Africa. J Neurol Sci 2010;295(1-2):38-40

6 Kim JS. Stroke in Asia: a global disaster. Int J Stroke 2014;9(7):856-857

7 Mehndiratta MM, Khan M, Mehndiratta P, Wasay M. Stroke in Asia: geographical variations and temporal trends. J Neurol Neurosurg Psychiatry 2014;85(12):1308-1312

8 Ghandehari K. Epidemiology of stroke in Iran. GMJ 2016;5:3-9

9 Caplan LR, ed. Caplan's stroke. New York: Cambridge University Press; 2016

10 Oliveira V, Kumutha JR, Narayanan E, et al. Hypothermia for encephalopathy in low-income and middle-income countries: feasibility of whole-body cooling using a low-cost servo-controlled device. BMJ Paediatr Open 2018;2(1):e000245

11 Bergan HA, Halvorsen PS, Skulstad H, Fosse E, Bugge JF. Does therapeutic hypothermia during extracorporeal 
cardiopulmonary resuscitation preserve cardiac function? J Transl Med 2016;14(1):345

12 Krawczyk P, Kołodziej G, Szpyra B, Andres J. Implementation of therapeutic hypothermia after cardiac arrest in intensive care units in Poland. Kardiol Pol 2013;71(3):270-274 (Polish Heart Journal)

13 Takeda Y, Kawashima T, Kiyota K, et al. Feasibility study of immediate pharyngeal cooling initiation in cardiac arrest patients after arrival at the emergency room. Resuscitation 2014;85(12):1647-1653

14 Ahmed AI, Bullock MR, Dietrich WD. Hypothermia in traumatic brain injury. Neurosurg Clin N Am 2016;27(4):489-497

15 Crompton EM, Lubomirova I, Cotlarciuc I, Han TS, Sharma SD, Sharma P. Meta-analysis of therapeutic hypothermia for traumatic brain injury in adult and pediatric patients. Crit Care Med 2017;45(4):575-583

16 Chandrasekaran PN, Dezfulian C, Polderman KH. What is the right temperature to cool post-cardiac arrest patients? Crit Care 2015;19:406

17 Kan P, Duckworth E, Germanwala AV, et al. Neurosurgery concepts: key perspectives on embolectomy for stroke with emergent large vessel occlusion (MR CLEAN), endonasal endoscopic craniopharyngioma resection, gamma knife radiosurgery for meningiomas, therapeutic hypothermia for severe traumatic brain injury. Surg Neurol Int 2015;6:165

18 Kurisu K, Yenari MA. Therapeutic hypothermia for ischemic stroke; pathophysiology and future promise. Neuropharmacology 2018;134(Pt B) :302-309

19 Andresen M, Gazmuri JT, Marín A, Regueira T, Rovegno M. Therapeutic hypothermia for acute brain injuries. Scand J Trauma Resusc Emerg Med 2015;23:42

20 Han Z, Liu X, Luo Y, Ji X. Therapeutic hypothermia for stroke: where to go? Exp Neurol 2015;272:67-77

21 Szczygielski J, Müller A, Mautes AE, et al. Selective brain hypothermia mitigates brain damage and improves neurological outcome after post-traumatic decompressive craniectomy in mice. J Neurotrauma 2017;34(8):1623-1635

22 Basiri B, Eghbalian F, Vakili Garmroodi K. Evolution of the therapeutic effects of induced local hypothermia in neonates with hypoxic-ischemic encephalopathy. Avicenna J Clin Med 2011;18:5-9

23 Ehsani V, Allahtavakoli M, Dashti M, et al. Effect of general hypothermia on the embolic model of stroke in the male rat. J Shaheed Sdoughi Univ Med Sci Yazd 2014;21:776-783

24 Allahtavakoli M, Kahnouei MH, Rezazadeh H, et al. Delayed combination therapy of local brain hypothermia and decompressive craniectomy on acute stroke outcome in rat. Iran J Basic Med Sci 2014;17(7):476-482

25 Hoseeini Kahnouei MA, Rezazadeh H, Mahmoudi MH, Purrashidy Basharabadi A, Alahtavakoli M. Protective effect of combination therapy of local brain hypothermia and decompressive craniectomy on stroke model in rat. J Mazandaran Univ Med Sci 2014;24(113):81-90

26 Knaus WA, Wagner DP, Draper EA, et al. The APACHE III prognostic system. Risk prediction of hospital mortality for critically ill hospitalized adults. Chest 1991;100(6):1619-1636

27 Soleimani M, Masoudi R, Bahrami N, Qorbani M, Sadeghi T. Predicting mortality rate of patients in critical care unit using APACHE-II index. Majallah-i Danishgah-i Ulum-i Pizishki-i Gurgan 2010;11:64-69

28 Motamed Al-shariati S, Rezaei E, BeiraghiToosi A. Comparison between acute physiology and chronic health evaluation system and abbreviated burn severity index (ABSI) in prediction of burn patient's mortality. Med Uni Zahedan J 2011;9:33-38

29 Wijdicks EF, Bamlet WR, Maramattom BV, Manno EM, McClelland RL. Validation of a new coma scale: the FOUR score. Ann Neurol 2005;58(4):585-593
30 Wolf CA, Wijdicks EF, Bamlet WR, McClelland RL. Further validation of the FOUR score coma scale by intensive care nurses. Mayo Clin Proc 2007;82(4):435-438

31 Iyer VN, Mandrekar JN, Danielson RD, Zubkov AY, Elmer JL, Wijdicks EF. Validity of the FOUR score coma scale in the medical intensive care unit. Mayo Clin Proc 2009;84(8):694-701

32 Cohen J. Interrater reliability and predictive validity of the FOUR score coma scale in a pediatric population. J Neurosci Nurs 2009;41(5):261-267, quiz 268-269

33 Tadrisi SD, Bahari N, Ebadi A, Madani SJ. Validity and reliability of coma scale (Four Score) in adult patient hospitalized in critical care units. Crit Care Nurse 2012;5:95-102

34 Kasner SE, Chalela JA, Luciano JM, et al. Reliability and validity of estimating the NIH stroke scale score from medical records. Stroke 1999;30(8):1534-1537

35 Hinkle JL. Reliability and validity of the National Institutes of Health Stroke Scale for neuroscience nurses. Stroke 2014;45(3):e32-e34

36 Kazemnejad LE, Rezaei S, Hosseini-Nejad M, Bakhshayesh EB, Saberi A, Keshavarz P. The applicability, concurrent validity and internal consistency reliability of the Persian version of the National Institutes of Health Stroke Scale (NIHSS): evidences for gender differences. Caspian J Neurol Sci 2016;2:18-28

37 Hutchison JS, Ward RE, Lacroix J, et al; Hypothermia Pediatric Head Injury Trial Investigators and the Canadian Critical Care Trials Group. Hypothermia therapy after traumatic brain injury in children. N Engl J Med 2008;358(23):2447-2456

38 Bayegan K, Janata A, Frossard M, et al. Rapid non-invasive external cooling to induce mild therapeutic hypothermia in adult human-sized swine. Resuscitation 2008;76(2):291-298

39 Jeong H-Y, Chang J-Y, Yum KS, et al. Extended use of hypothermia in elderly patients with malignant cerebral edema as an alternative to hemicraniectomy. J Stroke 2016;18(3):337-343

40 Krieger DW, Yenari MA. Therapeutic hypothermia for acute ischemic stroke: what do laboratory studies teach us. ? Stroke 2004;35(6):1482-1489

41 Schultheiss M, Schnichels S, Hermann T, et al. Hypothermia protects and prolongs the tolerance time of retinal ganglion cells against ischemia. PLoS One 2016;11(2):e0148616

42 Bi Y, Huan Y, Cai W, et al. Mild hypothermia in combination with minimally invasive evacuation of hematoma reduces inflammatory damage in patients via the nuclear factor-кB pathway. Exp Ther Med 2014;8(6):1717-1722

43 Alzaga AG, Cerdan M, Varon J. Therapeutic hypothermia. Resuscitation 2006;70(3):369-380

44 Nogueira AB, Nogueira AB, Esteves Veiga JC, Teixeira MJ. Multimodality monitoring, inflammation, and neuroregeneration in subarachnoid hemorrhage. Neurosurgery 2014;75(6):678-689

45 Dénes A, Ferenczi S, Kovács KJ. Systemic inflammatory challenges compromise survival after experimental stroke via augmenting brain inflammation, blood-brain barrier damage and brain oedema independently of infarct size. J Neuroinflammation 2011;8:164

46 Macleod MR, Petersson J, Norrving B, et al; European Hypothermia Stroke Research Workshop. Hypothermia for stroke: call to action 2010. Int J Stroke 2010;5(6):489-492

47 Lyden PD, Allgren RL, Ng K, et al. Intravascular Cooling in the Treatment of Stroke (ICTUS): early clinical experience. J Stroke Cerebrovasc Dis 2005;14(3):107-114

48 Poli S, Purrucker J, Priglinger M, et al. Rapid Induction of COOLing in Stroke Patients (iCOOL1): a randomised pilot study comparing cold infusions with nasopharyngeal cooling. Crit Care 2014;18(5):582

49 Tahir RA, Pabaney AH. Therapeutic hypothermia and ischemic stroke: a literature review. Surg Neurol Int 2016;7(Suppl 14) S381-S386 